\title{
Modified Modeling of Clay Paste Extrusion through a Circular Die: Beyond the Steady-State
}

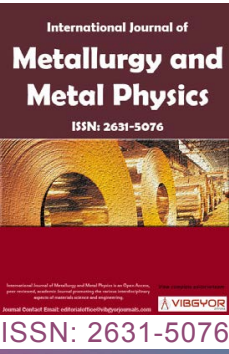

Henrique A Tajiri' ${ }^{*}$, Edson R de Pieri' and Hazim A Al-Qureshi ${ }^{3}$

${ }^{1}$ Department of Mechanical Engineering, CTC, Federal University of Santa Catarina, Florianopolis, Brazil

${ }^{2}$ Department of Automation and Systems, CTC, Federal University of Santa Catarina, Florianopolis, Brazil

${ }^{3}$ Graduate Program in Mechanical Science and Engineering, CTJ, Federal University of Santa Catarina, Joinville, Brazil

\begin{abstract}
The aim of this study is to develop a mathematical modeling of direct paste extrusion through a circular die going beyond the steady-state, where the coring point becomes evident. The proposed study considers a previous mathematical modeling of clay paste extrusion which did not consider the behavior beyond the steady-state. Therefore, it is proposed that the coefficient of friction is no longer constant after the steady-state. Moreover, beyond the coring point, two types of behavior can be noticed, an acceleration of the extrusion pressure decrease rate or an increase of the extrusion pressure. The latter behavior harms the ceramic industry since it can lead to die damage, lubrication problems, product defects and raise the production cost. This increase in the extrusion pressure, during the unsteady-state, can be regarded to the water loss and densification of the ceramic paste. Four types of clay were used in the present work and cylindrical specimens were extruded. Four cylindrical samples were prepared for the compression test to determine the effective compressive stress and friction coefficient between the clay and the punch. These two determined parameters were further used in the mathematical modeling of the extrusion process. The effective compressive stress varied from 0.07 up to $0.11 \mathrm{MPa}$. A friction coefficient of 0.134 was found from the compression test. In addition, after the coring point, extrusion pressures $50 \%$ greater than the steady-state were recorded. In conclusion, the mathematical modeling for the compression test and for the extrusion process demonstrated good correlation with the experimental points.
\end{abstract}

\section{Keywords}

Clay extrusion modeling, Coring point, Density, Plasticity

\section{Abbreviations and Greek Letters}

$A_{0}$ : Initial Area; $A_{f}$ : Final Area; $D_{0}$ : Initial Diameter; H: Height; Lc: Critical Length (Coring point); $\mathrm{F}$ : Instantaneous Axial Force; $\mathrm{P}_{\text {ave }}$ : Average Extrusion Pressure; $\mathrm{R}_{0}$ : Initial Radius; $\mathrm{R}_{\mathrm{f}}$ : Final Radius; z: Punch Travel; $\alpha$ : Semicone Angle of the Die; $\bar{\varepsilon}$ : Effective Strain; $\mu_{\text {comp }}$ : Coefficient of Friction Between Punch and Clay Paste; $\mu_{w}$ : Coefficient of Friction Between Wall and Clay Paste; $\sigma_{\text {ave }}$ : Average Extrusion Pressure; $\sigma_{r}$ : Radial Stress; $\sigma_{z}$ : Axial Stress; $\bar{\sigma}$ : Effective Stress; $\bar{\sigma}{ }_{\text {comp }}$ : Effective Stress of Compression

*Corresponding author: Henrique A Tajiri, Department of Mechanical Engineering, CTC, Federal University of Santa Catarina, Florianopolis, Brazil, Tel: $+55-48-988085257$

Accepted: January 19, 2019; Published: January 21, 2019

Copyright: (C) 2019 Tajiri HA, et al. This is an open-access article distributed under the terms of the Creative Commons Attribution License, which permits unrestricted use, distribution, and reproduction in any medium, provided the original author and source are credited.

Tajiri et al. Int J Metall Met Phys 2019, 4:027 


\section{Introduction}

There are few areas in technology in which development has met many application fields as extrusion. Initially, it was employed only for simple ceramic materials. Nevertheless, nowadays extrusion is employed in different areas such as ceramic, metallurgy, polymers industry, chemical or even food industry. For instance, Benbow, et al. mentioned some application of extruded parts such as earthenware pipes, thermocouple tubes, catalyst monoliths, and animal feeds [1].

Currently, many studies are being conducted in this area focusing on producing advanced ceramics by extrusion. Examples such as ceramic honeycombs, high-Al2O3 ceramics for insulation, and aerospace components were pointed out by Händle [2]. Besides that, tests which forecast the behavior of clay during extrusion, as well as mathematical modelling of some properties, specially plasticity, make the results difficult due to many parameters that are involved in the process. In the literature, there is no consensus regarding which method should be used to evaluate the plasticity to be chosen $[3,4]$. For instance, the Pferfferkorn's plasticity index, Atterberg's plasticity index, indentation, stress/strain curves, and rheological analysis are methods cited which aim to evaluate the plasticity of a ceramic [5].

Energy saving, flux regularity, and adequate extrusion pressure are factors which depends on the type of extruder used and plasticity of the clay paste [6]. The type of extruders can be classified according to the method which produces pressure to be applied to a paste. For example, if the pressure is generated by the forcing of two rolling surfaces, it is called rotary extrusion; if the pressure is produced by the use of rotating screws or augers, it is named screw's extruder; and, finally, if the pressure is achieved by casting the paste inside a cylinder pressed with a ram, it is termed ram extruder [1]. So far, the extrusion of ceramic paste has been studied and understood in a limited way [7]. Moreover, seldom are there studies in the literature which explore the behavior of the extruded clay beyond the unsteady-state. The reason for that is the fact that, historically, the extrusion of ceramic pastes was restricted to the manufacture of products of low cost such as the red ceramic industry which did not require a strict dimensional and quality control [8].
Reed JS defined plasticity in ceramics as a particular mode of mechanical behavior when a plastic material features a permanent deformation without fracture under shear stress greater than the yield strength of the material [3]. Moreover, in the literature, another issue is found concerning ceramic extrusion: There is no consensus among researchers regarding which method should be used to evaluate the plasticity to be chosen. For instance, Andrade, et al. listed 5 main methods to evaluate the plasticity of a ceramic paste: Pferfferkorn's plasticity index, Atterberg's plasticity index, indentation, stress/strain curves, and rheological analysis as methods used to evaluate the plasticity of a ceramic paste [5]. Even though there are diverse proposed methods to assess the plasticity of the paste, Dondi stated that they may not deliver equivalent results [4].

In metallurgy, Johnson $[9,10]$, studying the plane-strain extrusion of aluminum and lead, observed that the extrusion load decreased as the extrusion punch moved forward. However, the travel punch reached a point, before the unsteady-sate, which he named "coring point", also recognized by Avitzur [11] and Hoffmanner [12]. At this point, graphically, he perceived that there was a noticeable acceleration of the extrusion load decrease rate $[9,13]$. The phenomenon of the pressure rises near the end of both extrusion processes (direct and indirect extrusion) where the defect of a pipe or hole forms in the billet. This Johnson [9] coined as "coring point", that is the point at which the piston, or the end of the cylinder, upstream from the die, enters the plastic zone in front of the die. Therefore, a disturbance is initiated which causes termination of the steady phase of the flow pattern. Other authors [14] observed a different behavior for the coring point as stated by Johnson $[9,13]$. Instead of a decrease of the extrusion load, an increase of this load was detected, so the point of coring lay at the minimum extrusion load pressure [14]. For the extrusion of ceramics, this shift from the steady-state to the unsteady-state is also present $[1,15]$, but very little is discussed or explored about it.

Based on a mathematical model for extrusion of clay published by Andrade [16], a modification of the model to predict the effect of the unsteadystate on the extrusion pressure is proposed in this work. This focus on studying beyond the coring point is important, since this point is reached, an unsteady-state of the material behavior and high 
pressures are achieved. This significant increase in the extrusion pressure, in industry, gives a greater possibility of dealing with damage of the die and lubrication problems leading to products with defect and increasing costs.

\section{Theoretical analysis}

Equation in the compression process: For the sake of defining some parameters of the extrusion process, Flores, et al. proposed a mathematical modeling [17]. They considered the hypothesis that the cylindrical clay body, under compression stress, presents an axial and symmetrical deformation. Moreover, they stated that as the compression force is applied, the height of the specimen de- creased while its instantaneous radius increased. Using the equations from Levy-Mises for the plastic zone [18] and the equation from von Mises for the effective stress, they proposed the following mathematical modeling (Eq. 1) $[16,17]$ :

$F=-2 \pi \bar{\sigma}\left[-\frac{h}{2 \mu}\left(r_{f}+\frac{h}{2 \mu}\right)+\frac{h^{2}}{4 \mu^{2}} \exp \left(\frac{2 \mu r_{f}}{h}\right)\right]$

Where $F$ is the instantaneous axial force, $\bar{\sigma}$ the flow stress, $h$ the final height of the sample, $\mu$ the friction coefficient between the surface of the compression machine and the clay, and $r_{f}$ the final radius of the specimen.

Eq. 1 is used to assess the plasticity of the clay during the axial compression test. Additionally,

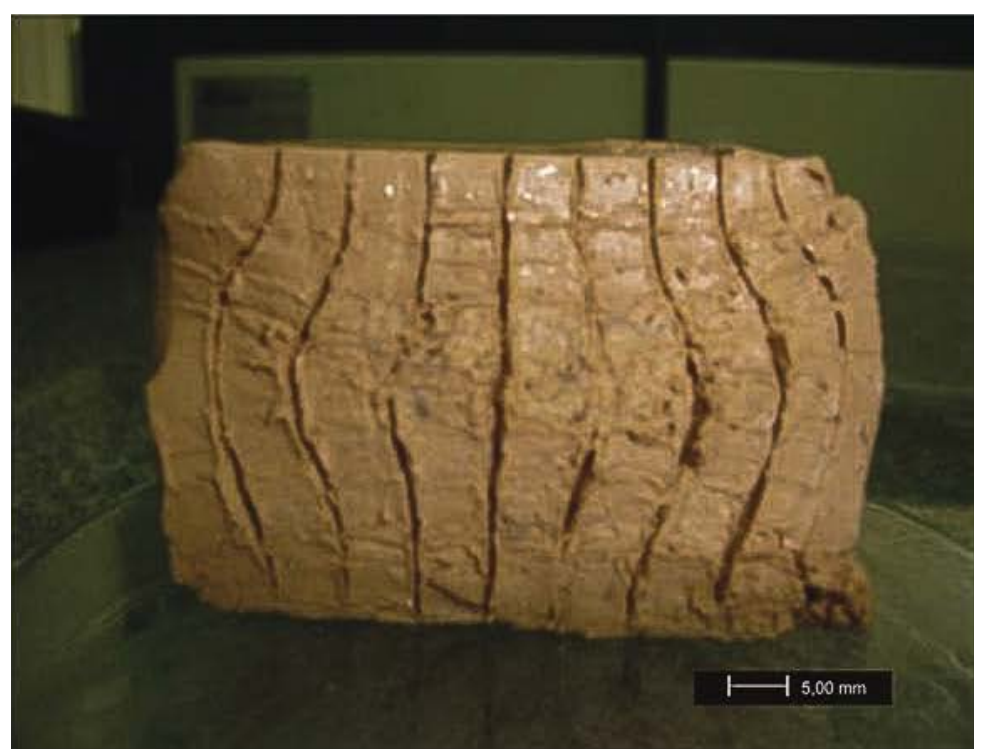

Figure 1: Sectioned clay paste sample showing strain lines representing the stress distribution [19].

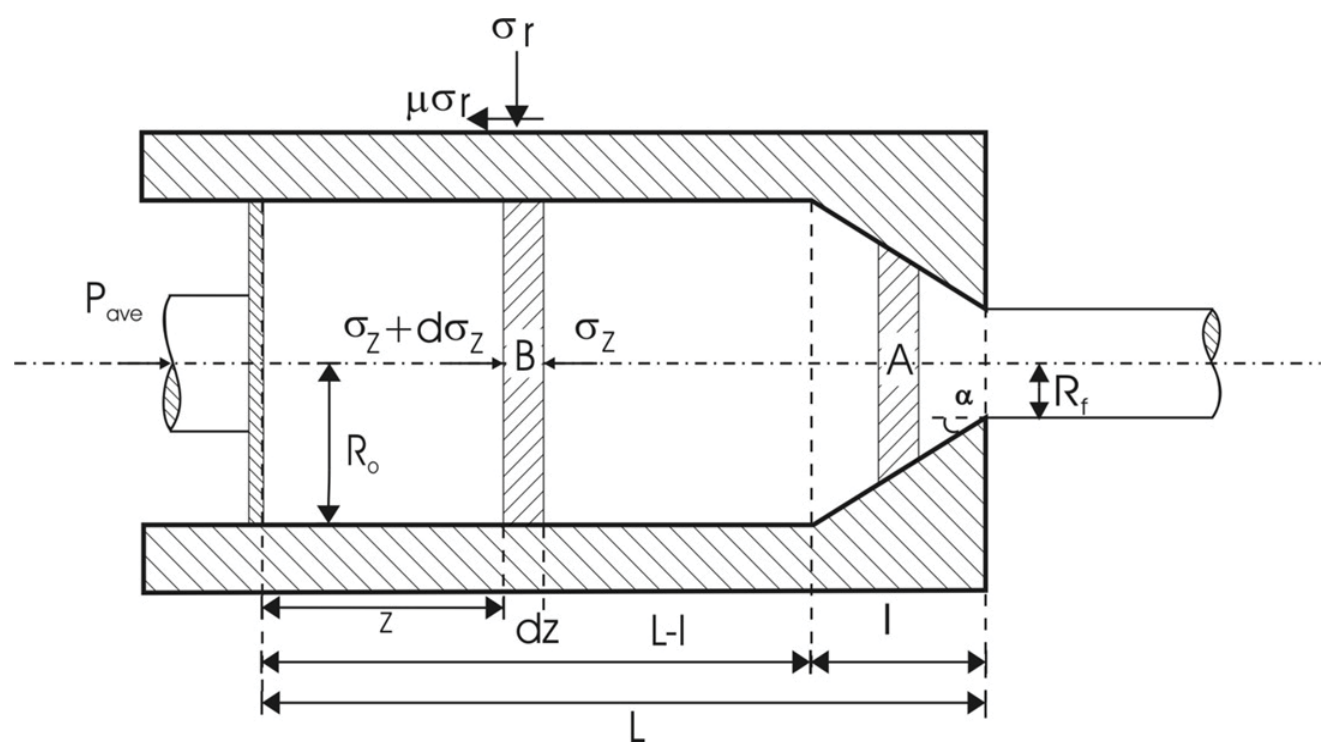

Figure 2: Diagrammatic sketch of extrusion of clay paste through a circular die with angular variation [16]. 
using Eq. 1 it is possible to determine the effective stress $(\bar{\sigma})$ and the friction coefficient $(\mu)$ between the clay and the punch by an iterative method. The flow stress was measured using different uniaxial compressive loadings as shown in Figure 1. It can be easily seen that barreling has occured, and this is due to the friction between the ends of the specimen and the deforming tools/punch. As a result, the coefficient of friction was included as one of the mathematical parameters to analyze the forces that act on a cylindrical clay compact and was also assumed to be constant according to Andrade, et al. [19].

Equation in the extrusion process considering the friction and the angular variation: The extrusion molding process consists of compelling a paste through a die with a desired final cross section. Moreover, it shortens its cross-sectional area from initial $\left(A_{0}\right)$ to final $\left(A_{f}\right)$ and expands its length. In the proposed model, it is assumed a steady-state during the extrusion process. Therefore, the ideal average extrusion pressure (considering no friction during the process $\mu_{\text {comp }}=\mu_{w}=0$ ) for uniform deformation can be expressed as (Eq. 2):

$$
\left.\sigma_{\text {ave }}\right|_{\mu=0}=1.5 \int_{0}^{\bar{\varepsilon}} \bar{\sigma} d \bar{\varepsilon}
$$

Where $\sigma_{\text {ave }}$ is the average extrusion pressure, $\mu$ is the coefficient of friction between the cylinder wall and the clay paste, 1.5 is the shear factor which is used to compensate the energy loss, mainly due to the friction and redundant work that are not included in equation, $\bar{\sigma}$ is the flow stress and $\bar{\varepsilon}$ is the flow strain.

In Eq. 2, it is possible to observe that it does not consider the friction in the cylinder wall; so, Eq. 3 is proposed, which takes into account the cylinder wall friction in the extrusion direction (Figure 2).

$$
d \sigma_{z}=\frac{4 \mu_{w} \sigma_{r}}{D_{0}} d z
$$

Where $\sigma_{z}$ is the axial stress, $\mu_{w}$ the coefficient of friction between the wall and the clay paste, $\sigma_{r}$ the radial stress, $z$ the punch travel and $D_{0}$ the initial diameter.

Observing, Figure 2, one can note that the diameter of the cylinder is constant, until reaching the conical part of the extruder (L-I). Moreover, considering the Levy-Mises relationships [20], which states that $\sigma_{r}=\sigma_{z}$, Eq. 4 is reached:

$$
\text { In } \sigma_{z}=\frac{4 \mu_{w} z}{D_{0}}+C
$$

Taking into account the boundary condition where $\sigma_{\text {ave }}\left(\mu_{w}=0\right)$ at $z=L_{c^{\prime}}$ considering that the total pressure can be written as $\left(\sigma_{z}\right)_{\text {total }}=\left(\sigma_{z}\right)_{\mu \neq 0}+$ $\left(\sigma_{z}\right)_{\mu=0}$, and the funneling effect [19], Eq. 5 and Eq. 6 can be derived:

$$
\begin{aligned}
& p_{\text {total }}=\left(\sigma_{z}\right)_{\text {total }}=\left\{1+\exp \left[\frac{4 \mu_{w}}{D_{0}}\left(z-L_{c}\right)\right]\right\} 1.5 \int_{0}^{\bar{\varepsilon}} \bar{\sigma} d \bar{\varepsilon} \\
& \bar{\sigma}=\sigma_{z}=-\overline{\sigma_{\text {comp }}} \exp \left[\frac{2 \mu}{h}\left(R_{f}-R_{0}\right)\right]
\end{aligned}
$$

Where $\overline{\sigma_{\text {comp }}}$ stands for the effective stress of compression, $R_{f}$ the final radius and $R_{0}$ the initial radius.

Combining Eq. 5 and Eq. 6, yields Eq. 7:

$$
p_{\text {woul }}=0.75 \frac{\overline{\sigma_{\text {comp }} z}}{\left(R_{f}-R_{0}\right) \mu_{\text {conp }}}\left\{1+\exp \left[\frac{2 \mu_{w}}{R_{0}}\left(z-L_{c}\right)\right]\right\}\left\{1-\exp \left[\frac{2 \mu_{\text {conp }}}{z}\left(R_{f}-R_{0}\right)\right]\right\}
$$

Eq. 7 does not consider a circular die with angular variation, it is only the expression for total extrusion pressure, when the semicone angle of the die $(\alpha)$ is equal to $90^{\circ}$. However, taking into account the angular variation of the die and making the pressure balance in the $A$ and $B$ region of the die, as can be seen in Figure 2, the average extrusion pressure can be determined, Eq. 8:

$$
\begin{aligned}
& P_{\text {ave }}=\frac{\overline{\sigma_{\text {comp }}}}{\left(R_{f}-R_{0}\right)} \frac{z}{2 \mu_{\text {conp }}}\left\{1-\exp \left[\frac{2 \mu_{\text {comp }}}{z}\left(R_{f}-R_{0}\right)\right]\right\} \\
& \left\{\left\{1+\frac{\left(1+\mu_{w} \cot \alpha\right)}{\mu_{w} \cot \alpha}\left[\left(\frac{R_{0}}{R_{f}}\right)^{2 \mu_{w} \cot \alpha}-1\right]\right\} \exp \left\{2 \mu_{w} \cot \alpha\left[-\frac{L_{c}}{R_{0}} \tan \alpha+\left(1-\frac{R_{0}}{R_{f}}\right)\right]\right\}-1\right\}
\end{aligned}
$$

Beyond the steady-state: After the point of coring, there are many significant changes in the mechanical and physical properties of the ceramic paste. Moreover, the punch proceeds to move forward, to the end of the matrix, so some operational parameters may change. As a result, the friction changes along the punch and the cylinder wall. In addition, it is assumed that the composition pressure is not anymore at a steady-state as in the previous stage. It becomes non-steady and it varies according to the punch movement. This action causes loss of water content and densification of the clay, and also changes the viscosity of the clay paste. It is well known that friction dominates the flow of the clay paste throughout the die. Hence it influences greatly the density along the extruded part after the coring point.

It is very difficult to derive these variations of the parameters mathematically. However, the initial 
Table 1: Chemical composition in weight percentage of the AC12 clay obtained by XRF.

\begin{tabular}{|l|l|l|l|l|l|l|l|l|l|l|l|}
\hline Oxide & $\mathrm{SiO}_{2}$ & $\mathrm{Al}_{2} \mathrm{O}_{3}$ & $\mathrm{Fe}_{2} \mathrm{O}_{3}$ & $\mathrm{CaO}$ & $\mathrm{Na}_{2} \mathrm{O}$ & $\mathrm{K}_{2} \mathrm{O}$ & $\mathrm{MnO}$ & $\mathrm{TiO}_{2}$ & $\mathrm{MgO}$ & $\mathrm{P}_{2} \mathrm{O}_{5}$ & $*$ L.F. \\
\hline Wt.\% & 69.41 & 18.51 & 2.20 & 0.05 & 0.08 & 2.91 & $<0.01$ & 0.73 & 0.82 & 0.14 & 5.15 \\
\hline
\end{tabular}

*L.F. stands for loss on fire $\left(1000^{\circ} \mathrm{C}\right)$.

trial is to assess the varieties of the experimental entries, considering also the Arrhenius relation. In this work it is suggested that the relationship among ram displacement, coefficient of friction, and density variation is given by the following equation (Eq. 9):

$$
\left.\mu_{x_{n}}=\mu_{x_{n-1}}\left[\frac{\rho_{x_{n}}}{\rho_{x_{n-1}}}\right]^{x_{n}}\right]_{x_{n-1}}
$$

Where $\mu_{x_{n}}, \mu_{x_{n-1}}$ are the coefficient of friction at the $x_{n}$ and $x_{n-1}$ positions of the ram. Similarly, the densities are the position $\rho_{x_{n}}$ and $\rho_{x_{n-1}}$, respectively.

De Wit, et al. demonstrated in a conference held in Amsterdam that the density of some clay minerals, can have their densities doubled depending on the moisture content on the material [21]. In fact, the plot of $\rho_{x_{n}}$ against $\rho_{x_{n-1}}$ can be considered linear and $\rho_{x_{n-1}}$ have their approximate relationship, expressed in Eq. 10:

$$
\rho_{x_{n}}=2 \rho_{x_{n-1}}
$$

The above equation makes the solution of Eq. 9 easier and enhance the extrusion pressure, given in Eq. 8 at any ram position, which would predict the final extrusion pressure as expressed in Eq. 11:

$$
\begin{aligned}
& P_{\text {ave }} \frac{\frac{}{\text { comp }}}{(R-R)} \frac{2}{2}\left\{1-\exp \left[\frac{22 /}{2}\left(R_{f}-R\right)\right]\right\} \\
& \left\{\left\{1+\frac{(1 \mu \cot \alpha)}{\mu_{w} \cot \alpha}\left[\left(\frac{R_{0}}{R_{f}}\right)^{2 \mu \cot \alpha}-1\right]\right\} \exp \left\{2 \mu \cot \alpha\left[-\frac{L}{R} \tan \alpha+\left(1-\frac{R_{0}}{R_{f}}\right)\right]\right\}-1\right\}
\end{aligned}
$$

\section{Material and Methods}

The materials and methods were based on Andrade and Flores previous works $[16,17]$. The material used was a clay AC12 supplied by Colorminas. The chemical composition of the clay is shown in Table 1.

The as received AC12 clay was disaggregated using a dry ball milling for 20 min, followed by a sieving process through a mesh of $420 \mu \mathrm{m}$. One $\mathrm{kg}$ of the disaggregated and sieved material was collected. Moreover, in order to quantify the humidity percentage in the clay, approximately $10 \mathrm{~g}$ of the sieved clay were placed in an oven at $110 \pm 5{ }^{\circ} \mathrm{C}$ for $24 \mathrm{~h}$ for calcination. From the results

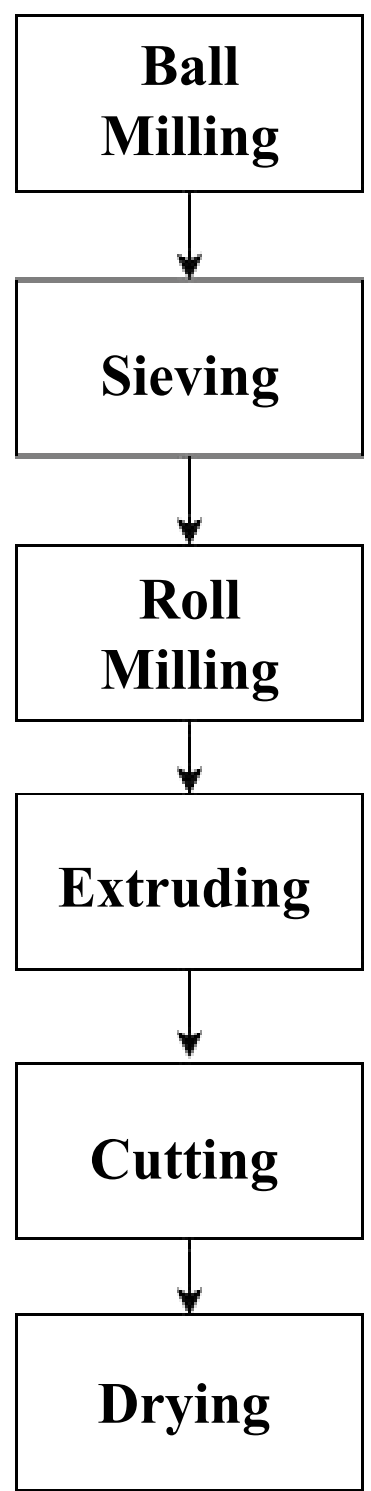

Figure 3: Experimental flowchart of the ceramic samples.

obtained by the calcination of the clay, samples with a moisture content of $55.2 \%$ were prepared and homogenized via mechanical mixing and left in a sealed plastic container for $24 \mathrm{~h}$. The whole experimental procedures to produce the cylindrical specimen is shown in Figure 3. The moisture content of $55.2 \%$ was chosen since this moisture content lies between the Atterberg's plastic and liquid limits. Samples with moisture content near the liquid limit do not present enough green strength, and some manometers may not have 
enough accuracy to measure its pressure. On the other hand, specimens near the plastic limit present higher extrusion pressure, being not so interesting in industry.

In order to obtain the specimens for the compression test, cylindrical samples were prepared manually in PVC molds with diameter and height of 17.0 and 23.0, respectively. Then, four specimens were used for the uniaxial compression test, using a TA-XT2i (Stable Micro System) machine, with velocity of $0.1 \mathrm{~mm} / \mathrm{min}$ and cell of $25 \mathrm{kgf}$. Finally, the samples had their average diameter measured by means of digital photographs and use of an image processing software, ImageTool. With the compression test results, it was possible to determine the effective compressive stress and the friction coefficient between the clay paste and the punch.

For the extrusion process, the disaggregated and sieved clay was roll milled using a Gelenski LIG-05 machine, for better disaggregation of the granules and better homogenization of the clay paste. Finally, the paste was extruded using a Gelenski MVIG-05 machine. In order to measure the extrusion pressure a manometer was installed between the barrel and the interchangeable die. The manometer had capacity to measure up to 20 $\mathrm{kgf} / \mathrm{cm}^{2}$ with a graduated scale of $0.1 \mathrm{kgf} / \mathrm{cm}^{2}$.

\section{Results and Discussion}

Prior to verify the proposed mathematical modeling expressed in Eq. 10, it is important to find the effective stress of the clay. As mentioned before, it can be determined when the clay is subjected to uniaxial compression stress. In addition, in order to evaluate and validate the mathematical modeling proposed for the uniaxial compression test (Eq. 1), a published work from Guilherme, et al. [22] was chosen and the mathematical model was applied. The load-radial curves for different materials and humidity percentages are shown in Figure 4.

As it can be seen in Figure 4, at first, there is a small elastic strain with a subsequent relatively high plastic strain. In addition, it is possible to observe a good correlation between the experimental points and the theoretical curves. Using Eq. 1, and applying the iterative process, it was possible to determine the effective stress of compression and the coefficient of friction between the punch and the clay paste. Furthermore, the calculated effective compressive flow stress for Terracotta, Porcelain and Earthenware were respectively, $0.08,0.11$, and $0.07 \mathrm{MPa}$. When compared to the paste bulk yield values published by Guilherme, et al. [22] for these materials, these values are in the same range of magnitude. Moving to the friction coefficient values, applying the iterative process for Eq. 1, all the materials presented the same friction coefficient, 0.134 . Contrasting with the calculated values of static friction from Guilherme, et al. [22], a greater difference was found for Porcelain ( $\mu=0.387)$, while for Terracotta $(\mu=0.134)$ and Earthenware $(\mu=0.147)$, it was observed no or little difference.

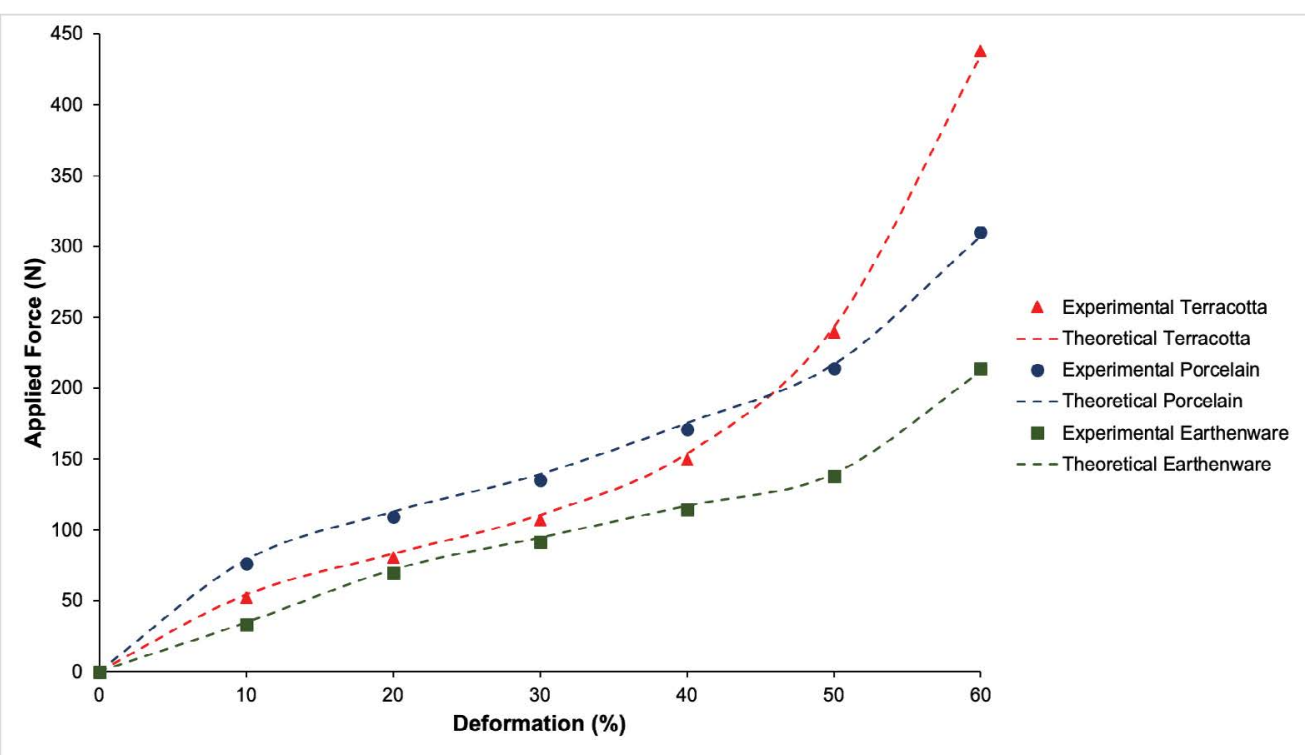

Figure 4: Experimental points and theoretical curves (dashed curves) from compression test. Terracotta with $25 \%$ of humidity, Porcelain with $31 \%$ of humidity, and Earthenware with $25.3 \%$ of humidity. 


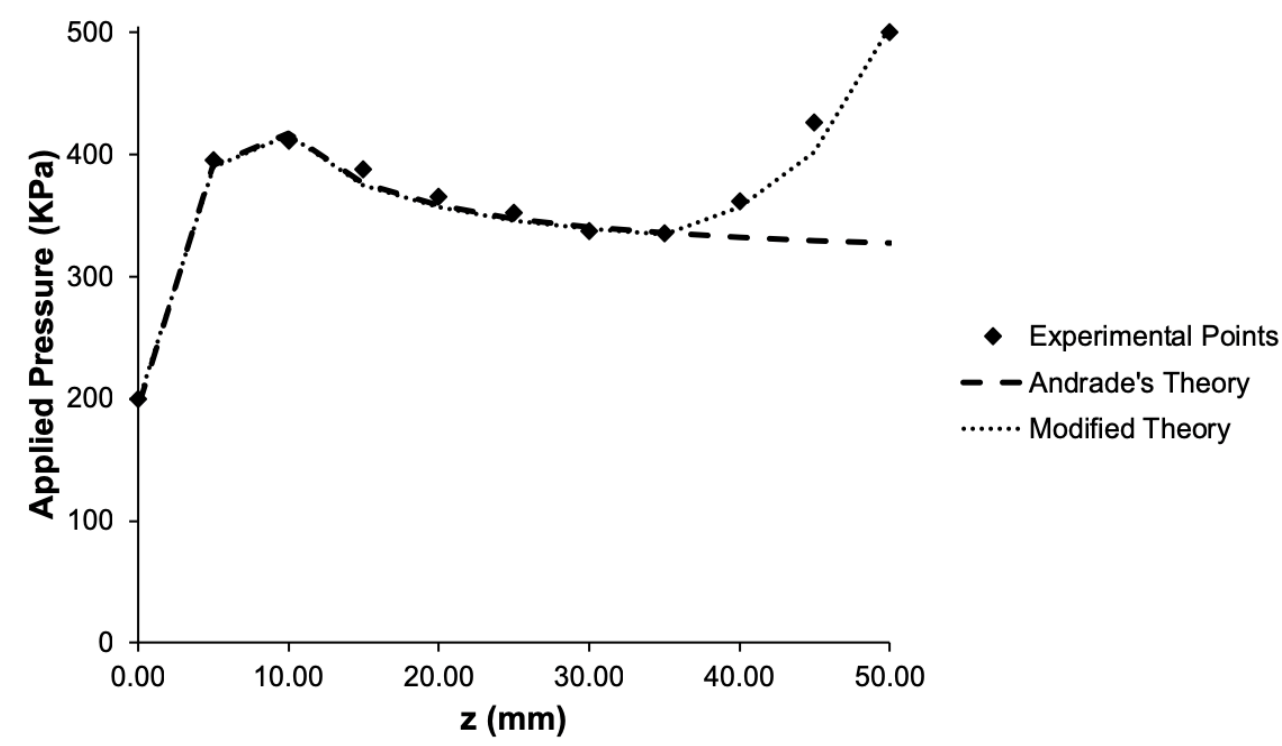

Figure 5: Comparison among experimental (diamond marks), Andrade (dashed line) [16] and Modified theoretical (round dot line) extrusion pressure varying the punch travel distance.

Table 2: Extrusion pressure comparison among experimental, Andrade's theoretical [16] and Modified Andrade's theoretical extrusion pressure for AC12 clay through a circular die, considering an angular variation.

\begin{tabular}{|l|l|l|l|l|l|}
\hline $\begin{array}{l}\text { Punch } \\
\text { travel } \\
(\mathbf{m m})\end{array}$ & $\begin{array}{l}\text { Experimental } \\
\text { extrusion } \\
\text { pressure (kPa) }\end{array}$ & $\begin{array}{l}\text { Andrade } \\
\text { theoretical } \\
\text { extrusion } \\
\text { pressure } \mathbf{( k P a )}\end{array}$ & $\begin{array}{l}\text { Difference between } \\
\text { Andrade and } \\
\text { experimental } \\
\text { pressure } \mathbf{( \% )}\end{array}$ & $\begin{array}{l}\text { Modified } \\
\text { theoretical } \\
\text { extrusion pressure } \\
\text { (kPa) }\end{array}$ & $\begin{array}{l}\text { Difference between } \\
\text { modified and } \\
\text { experimental } \\
\text { pressure (\%) }\end{array}$ \\
\hline 0.10 & 200.0 & 197.5 & -1.26 & 196.8 & -1.63 \\
\hline 5.00 & 395.0 & 391.0 & -1.03 & 389.5 & -1.40 \\
\hline 10.00 & 411.0 & 417.3 & 1.51 & 415.8 & 1.15 \\
\hline 15.00 & 388.0 & 376.4 & -3.07 & 375.1 & -3.45 \\
\hline 20.00 & 365.0 & 357.9 & -1.97 & 356.6 & -2.34 \\
\hline 25.00 & 352.0 & 347.4 & -1.32 & 346.1 & -1.69 \\
\hline 30.00 & 337.0 & 340.6 & 1.06 & 339.4 & 0.70 \\
\hline 35.00 & 335.0 & 335.9 & 0.25 & 334.6 & -0.11 \\
\hline 40.00 & 362.0 & 332.4 & -8.92 & 356.6 & -1.50 \\
\hline 45.00 & 426.0 & 329.7 & -29.22 & 401.6 & -6.08 \\
\hline 50.00 & 500.0 & 327.5 & -52.66 & 504.3 & 0.85 \\
\hline
\end{tabular}

For the extrusion curve, it was used a previously published work from Andrade [16] and reproduced for evaluating and validating a modified theory. Figure 5 displays the variation of the applied extrusion pressure as a function of the distance travelled by the piston. Three phases can be recognized in Figure 5: A coining phase, marked by compression of the ceramic paste; a steadystate phase, where the pressure is stabilized and the extrusion continues steadily; and an unsteadystate phase, also called as coring point, showing an evident increase in the extrusion pressure. As it can be noted, for Andrade's curve it is possible to notice only two phases the coining and the steady-state phase, once in his mathematical modeling [16], he did not consider implications of the coring point.

Figure 5 shows a good correlation between the experimental points and the modified theory throughout the entire curve. Even though, Andrade's theory shows a good fit up to the unsteady-state phase, it fails to neglect the coring point. Moreover, for this case, the coring point lays after $35 \mathrm{~mm}$ of ram displacement.

Table 2 highlights the differences in percentage between the experimental points and both theories (Andrade and Modified). One trend can be noticed for Andrade's theory, subsequently 
to the coring point, as the piston moves forward, the extrusion pressure difference increases in a nonlinear fashion. In addition, pressure difference up to $53 \%$ can be reached. On the other hand, for the Modified theoretical curve, pressure difference greater than $7 \%$ was not observed.

\section{Conclusion}

In this work it was possible to apply mathematical modeling successfully. The theoretical curves showed good agreement with the experimental data for both compression tests and extrusion processes. Moreover, it was possible to develop a mathematical model for the extrusion of clay paste to analyze the pressure beyond the steadystate phase. The coefficient of friction in the unsteady-state regime was no longer constant, since the ceramic past became drier and denser. It is interesting to predict the coring point, since after reaching that point, high pressures can be achieved. The expression for the variation of the coefficient of friction was proposed in the unsteady-state zone. This is fundamental for predicting the total extrusion pressures. The good correlation shown by the proposed theory makes it a potential tool for the assessment of clay material with optimized properties. Additionally, with this theory it will be possible to manufacture extrusion equipment accurately.

\section{Acknowledgements}

The authors wish to thank the Departments of Mechanical and Chemical Engineering, in UFSC for the use of the facilities and CNPq for partially financing the project and grants for the authors.

\section{Competing Interests}

Authors have declared that no competing interests exist.

\section{References}

1. Benbow J, Bridgwater J (1993) Paste flow and extrusion. Oxford: Clarendon Press.

2. Händle $F$ (2007) Extrusion in ceramics. Berlin, New York: Springer.

3. Reed JS (1995) Principles of ceramics processing. ( $2^{\text {nd }}$ edn), Wiley \& Sons, Chichester, New York.

4. Dondi M (2006) Caracterização tecnológica dos materiais argilosos: Métodos experimentais e interpretação dos dados. Revista Cerâmica Industrial 11: 36-40.

5. Andrade FA, Al-Qureshi HA, Hotza D (2011)
Measuring the plasticity of clays: A review. Applied Clay Science 51: 1-7.

6. Ribeiro MJ, Ferreira JM, Labrincha JA (2005) Plastic behaviour of different ceramic pastes processed by extrusion. Ceramics International 31: 515-519.

7. Burbidge AS, Bridgwater J (1995) The single screw extrusion of pastes. Chemical Engineering Science 50: 2531-2543.

8. Macedo RS, Menezes RR, Neves GA, Ferreira HC (2008) Estudo de argilas usadas em cerâmica vermelha. Cerâmica 54: 411-417.

9. Johnson W (1956) Experiments in plane-strain extrusion. Journal of the Mechanics and Physics of Solids 4: 269-282.

10. Johnson W (1959) An elementary consideration of some extrusion defects. Applied Scientific Research, Section A 8: 52-60.

11. Avitzur B (1967) Steady and unsteady state extrusion. J Engng Ind, 175.

12. Hoffmanner AL (1970) Metal forming interrelation between theory and practice: Proceedings of a symposium on the relation between theory and practice of metal forming, held in Cleveland. Plenum Press.

13. Dodeja LC, Johnson W (1957) The cold extrusion of circular rods through square multiple hole dies. Journal of the Mechanics and Physics of Solids 5: 281-295.

14. Sturgess CEN, Dean TA (1979) Breakthrough pressures in lubricated extrusion. Journal of Mechanical Working Technology 3: 119-135.

15. Janney MA (1995) Plastic forming of ceramics: Extrusion and injection moulding, in Ceramic Processing. Springer Netherlands: Dordrecht, 174211.

16. Andrade FA (2009) Modelamento Matemático do Comportamento Plástico do Sistema Argila-água no Processo de Extrusão, in Programa de PósGraduação em Ciência e Engenharia de Materiais. Universidade Federal de Santa Catarina.

17. Flores OJU, Mendes L, Novaes de Oliveira AP, Fredel MC, Al-Qureshi HA, et al. (2006) Modelo matemático aplicado à avaliação da plasticidade de argilas.

18. Avitzur B, Fueyo J, Thompson J (1967) Analysis of plastic flow through inclined planes in plane strain. Journal of Engineering for Industry 89: 361-375.

19. Andrade FA, Al-Qureshi HA, Hotza D (2013) Modeling 
of clay paste extrusion through a rectangular die. International Journal of Advanced Materials and Technologies, 1.

20. Hoffman O, Sachs G (1953) Introduction to the theory of plasticity for engineers. McGraw-Hill.

21. De Wit CT, Arens PL (1950) Moisture content and density of some clay minerals and some remarks on the hydration pattern of clay. Transactions of the International Congress of Soil Science, 2.

22. Guilherme P, Ribeiro MJ, Labrincha JA (2009) Behaviour of different industrial ceramic pastes in extrusion process. Advances in Applied Ceramics 108: 347-351. 